\title{
RESENHA \\ O fim do império cognitivo: a afirmação das epistemologias do Sul
}

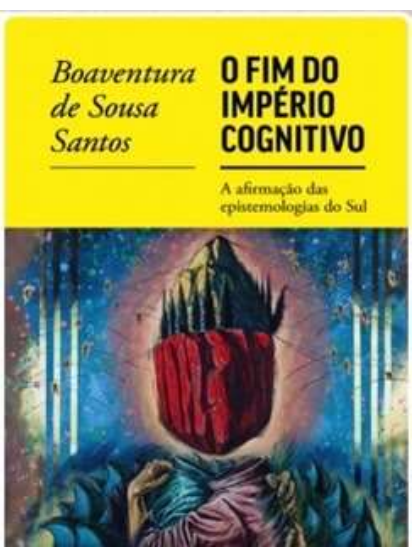

\author{
Andréa Thees 1 (1: \\ Universidade Federal do Estado do Rio de Janeiro \\ Rio de Janeiro (UNIRIO), Escola de Educação, Departamento de \\ Didática, Rio de Janeiro, RJ, Brasil
}

SANTOS, Boaventura de Souza. O fim do império cognitivo: a afirmação das epistemologias do Sul. Belo Horizonte: Autêntica Editora, 2019.

...um abraço Magnânimo e carismático é uma interrelação, promissora de compreensão e criação de mundos possíveis.

(Mário Vitória, 2015)

No dia 15 de novembro de 2020, completaram-se os 80 anos do professor e poeta Boaventura de Souza Santos. Autor de uma obra extensa e intensa, esse influente sociólogo, doutor em Sociologia do Direito, é professor catedrático aposentado da Faculdade de Economia da Universidade de Coimbra, onde criou o Centro de Estudos Sociais (CES), um prestigiado centro de investigação do qual é diretor emérito e Distinguished Legal Scholar da Faculdade de Direito da Universidade de Wisconsin-Madison. Boaventura atua, ainda, como coordenador científico do Observatório Permanente da Justiça Portuguesa.

Antes de iniciar a resenha do texto em si, alguns detalhes do livro O Fim do Império Cognitivo merecem ser destacados. Por exemplo, os elementos que compõem a sua capa. A começar pelo título, no qual Boaventura anuncia o fim do império cognitivo e a afirmação das epistemologias do Sul. Aqui começam algumas inquietações que apoiam a reflexão sobre qual autoridade e sobre qual domínio estaria sendo interpretado o conhecimento humano. Talvez seja possível seguir questionando como têm sido produzidas e validadas as teorias do conhecimento que se afirmam na perspectiva das epistemologias do Sul.

Submetido em: 26/06/2021 Aceito em: 18/08/2021 Publicado em: 03/09/2021

\footnotetext{
${ }^{1}$ Doutora em Educação pelo Programa de Pós-Graduação em Educação da UNIRIO. Professora Adjunta da Universidade Federal do Estado do Rio de Janeiro. Endereço para correspondência: Rua Santa Clara, 303/803 - Rio de Janeiro - RJ. Email: andrea.thees@unirio.br
} 
Ainda sobre os elementos da capa, observam-se dois corpos sem cabeça na pintura de Mário Vitória, denominada Magnanim@s, de 2015. Ambos se abraçam sob um objeto em formato de coração, mas semelhante visualmente a uma grande rocha dividida em duas partes: uma externa, representando uma montanha, e outra interna, representando o magma terrestre. $\mathrm{O}$ bloco parece tentar se desprender, mas o movimento de ascensão está sendo evitado por linhas que simulam cabos por onde se equilibram outros corpos segurando barras de apoio. Segundo Mário Vitória² , "um 'Abraço', realmente magnânimo, é aquele que olha aos mais de 36 milhões de escravos que temos neste momento no mundo". A partir dessa explicação, é permitido submergir e absorver o contexto de afirmação das epistemologias do Sul que Magnanim@s é capaz de inspirar.

Em O Fim do Império Cognitivo, Boaventura descreve os contextos teórico, metodológico e pedagógico nos quais se apoiam as epistemologias do Sul, conceito elaborado pelo autor e que desafia o domínio do pensamento eurocêntrico. Logo na introdução do livro, ao desenvolver a concepção do que seriam as epistemologias do Sul, Boaventura está se referindo

à produção e à validação de conhecimentos ancorados nas experiências de resistência de todos os grupos sociais que têm sido sistematicamente vítimas da injustiça, da opressão e da destruição causadas pelo capitalismo, pelo colonialismo e pelo patriarcado (SANTOS, 2019, p. 17)

Dessa forma, para o autor, essas experiências encontram-se no âmbito do Sul anti-imperial, um Sul epistemológico e não geográfico, cujos conhecimentos se originam em lutas sociais e políticas, não podendo ser separados delas.

Originados nas lutas e nos movimentos sociais, esses conhecimentos são provenientes de experiências de povos marginalizados que resistem ativamente ao capitalismo, ao colonialismo e ao patriarcado, estabelecendo maneiras alternativas de mobilização política e de ativismo. Essas formas de conhecimento, geralmente desacreditadas, apagadas e ignoradas pelas culturas dominantes do Norte global, representam a possibilidade de uma mudança que garanta justiça cognitiva global.

Para Boaventura, essa mudança epistemológica afeta diretamente os grupos sociais oprimidos no sentido de estabelecer uma representação do mundo conforme os seus próprios termos, buscandose transformação seguindo suas próprias aspirações. Ao mesmo tempo, o autor recupera a ideia de que existem alternativas potenciais para uma mudança epistemológica e reconhece que as lutas contra a opressão continuam a ter lugar no mundo. Para tal, ele defende que a transformação do mundo e a sua constante reinterpretação são tarefas coletivas que acontecem simultaneamente e não podem se separar.

${ }^{2}$ Em postagem no Facebook. Disponível em: https://bit.ly/3hKWpCC. Acesso em: 30 ago 2020. 
Em síntese, os conhecimentos e os saberes resgatados pelas epistemologias do Sul estão intrínsecos às práticas de resistência e de opressão, sendo que conhecimento e saber são palavras que devem ser entendidas como sinônimas. Outra perspectiva que Boaventura destaca para compreendermos a que se referem as epistemologias do Sul está em evitar a crença na unicidade de uma epistemologia do Norte e de outra do Sul, bem como em uma espécie de dualidade entre elas. Seus argumentos indicam que não há intenção de substituir epistemologias, nem de colocar o Sul no lugar do Norte, pois “a questão não consiste em apagar as diferenças entre norte e sul, e sim em apagar as hierarquias de poder que os habitam" (SANTOS, 2019, p. 26).

Deriva dessa interpretação uma divisão do mundo em Norte e Sul através de linhas imaginárias, gerando uma espécie de modelo epistêmico moderno ocidental, classificado pelo autor como um pensamento abissal. Neste livro, Boaventura Souza Santos revela que as experiências, os saberes e os atores sociais são demarcados por uma linha abissal que vem suprimindo, silenciando e marginalizando aqueles saberes que estão do outro lado da linha e que se tornam inexistentes pelos saberes que estão desse lado linha. Segundo Santos (2019, p. 28), "especialmente, quando resistem às exclusões abissais causadas pelo capitalismo, pelo colonialismo e pelo patriarcado".

Os problemas, as questões e os desafios epistemológicos, conceituais e analíticos levantados nesse livro foram separados e organizados por Boaventura em três partes. Na primeira, que introduz as epistemologias pós-abissais, ele descreve as bases das epistemologias do Sul e os problemas que surgem quando se confrontam as epistemologias do Sul com as do Norte. Na segunda parte, descrita como as metodologias pós-abissais, são tratadas as reconstruções teóricas, metodológicas e conceituais decorrentes da pesquisa realizada em consonância com as epistemologias do Sul. Finalmente, a terceira apresenta as pedagogias pós-abissais que têm a ver com os desafios pedagógicos colocados pelas epistemologias do Sul.

Para compor a primeira parte do livro, uma introdução às epistemologias pós-abissais, Boaventura se utiliza de cinco capítulos. No primeiro, estão descritos os principais instrumentos das epistemologias do Sul por meio de conceitos-chave. Nesse item, o autor aborda a linha abissal e os vários tipos de exclusão social criados por ela, distinguindo entre exclusões abissais e não abissais, a sociologia das ausências e a das emergências, as ecologias de saberes e a tradução intercultural, a artesania das práticas, todos entendidos como percursos para as epistemologias do Sul.

As respostas dadas às objeções normalmente levantadas pelas epistemologias do Norte são tratadas no capítulo 2, tendo como base os conceitos de ciência, de relativismo e de objetividade. No capítulo 3, as questões da autoria do conhecimento e do conhecimento escrito e oral são analisadas, bem como as questões epistemológicas específicas das epistemologias do Sul. Já os conceitos de luta e de experiência, centrais para os saberes das epistemologias do Sul, são discutidos no capítulo 4. 
Segue-se o capítulo 5, no qual Boaventura defende a corporeidade ou corporalidade do conhecimento, afastando-se da distinção mente/corpo e avançando no entendimento de conhecimento incorporado. Nesse capítulo, a corporização do conhecimento pode ser entendida por meio do corpo moribundo, do corpo sofredor e do corpo jubiloso, três experiências de corporização especialmente relacionadas às epistemologias do Sul. Por fim, o autor encerra essa parte do livro discutindo a ideia de aquecimento da razão, como denominou o momento em que razões e emoções se encontram e mobilizam a vontade e a capacidade de lutar contra a dominação e a opressão.

$\mathrm{Na}$ parte intermediária do livro, quatro capítulos foram reservados para Boaventura rever as metodologias pós-abissais, provenientes de pesquisas realizadas. As principais questões referentes ao uso de metodologias de pesquisa, consonantes com as epistemologias do Sul e voltadas para investigar as lutas sociais, são introduzidas no capítulo 6. Nele o autor defende a necessidade de descolonizar as ciências sociais, buscando usar metodologias não extrativistas fundamentadas em relações sujeito-sujeito e não em relações sujeito-objeto. Os capítulos 7, 8 e 9 se complementam e evidenciam o contexto existencial no qual as metodologias orientadoras da investigação pós-abissal devem ser postas em prática, bem como as dimensões sensoriais e emocionais da investigação pósabissal e, enfim, as formas de desmonumentalização do conhecimento escrito.

Boaventura aborda as pedagogias pós-abissais e as implicações pedagógicas das epistemologias do Sul na terceira e última parte de seu livro. O capítulo 10 ressalta as formas como as pedagogias podem contribuir para produzir e para reforçar articulações entre as lutas e os movimentos sociais, construindo assim a globalização contra-hegemônica, um dos principais objetivos das epistemologias do Sul. No Capítulo 11, o autor destaca a pedagogia do oprimido, de Paulo Freire, e a ação-investigação participativa, de Orlando Fals Borda, ficando os desafios e as tarefas que implicam a descolonização da universidade ocidental ou ocidentalizada para serem discutidos no capítulo seguinte. Desse modo, Boaventura discorre sobre o papel fundamental da educação popular e sobre alguns dos caminhos através dos quais a universidade poderá florescer enquanto pluriversidade e subversidade.

O livro de Boaventura estabelece contribuições fundamentais para a produção de conhecimentos em conformidade com as epistemologias do Sul, que se constituem por via de um amplo panorama de conhecimentos, metodologias e pedagogias pós-abissais. Seu principal objetivo é conduzir a resistência contra a injustiça, a exclusão e a discriminação que o norte global, capitalista, colonialista e patriarcal, impõe ao sul global.

Por fim, reforçando a premissa de Santos (2019, p. 411) de que "a credibilidade de qualquer forma de conhecimento será avaliada segundo o seu contributo para o reforço da resistência e para a prevenção da resignação", segue uma indicação que resgata e valoriza as experiências sociais de 
modos capacitadores, ou seja, "de modos que reforcem as lutas contra as três principais formas modernas de dominação: o capitalismo, o colonialismo e o patriarcado".

Logo, encerrando essa resenha, sugerem-se duas aulas complementares ${ }^{3}$, cujas temáticas fazem parte desse livro, ministradas por Boaventura no Centro de Estudos Sociais da Universidade de Coimbra, intituladas "Metodologias pós-abissais: luta, experiência, corpo e autoria" e "Pedagogias pós-abissais: as Epistemologias do Sul e a defesa da Universidade".
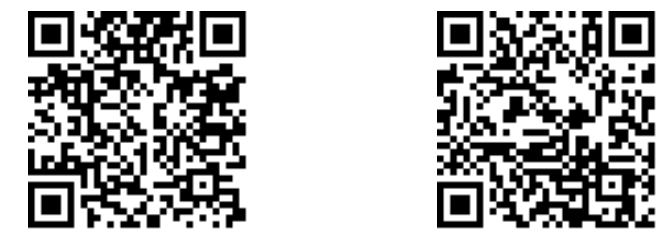

\section{Referência}

SANTOS, Boaventura de Souza. O fim do império cognitivo: a afirmação das epistemologias do Sul. Belo Horizonte: Autêntica Editora, 2019

3 Para acessar, basta apontar a câmera do celular para um dos QRCode acima, ou clicar no endereço: https//:www.youtube.com/user/canalces. Acesso em 5 set 2020 